\title{
Comparison of the Effectiveness of Combined Diode Laser and GLUMA Bonding Therapy With Combined Diode Laser and 5\% Sodium Fluoride Varnish in Patients With Dentin Hypersensitivity
}

\author{
Mohammad Asna Ashari ${ }^{1}$, Amirreza Berijani², Fahimeh Anbari ${ }^{3 * \mathbb{C}}$, Zahra Yazdani $^{4}$, Amin Zandian $^{5}$ \\ ${ }^{1}$ Laser Application in Medical Sciences research center, Shahid Beheshti University of Medical Sciences, Tehran, Iran \\ ${ }^{2}$ Graduated student, School of Dentistry, Shahid Beheshti University of Medical Sciences, Tehran, Iran \\ ${ }^{3}$ Oral Medicine Department, School of Dentistry, Shahid Beheshti University of Medical Sciences, Tehran, Iran \\ ${ }^{4}$ School of Dentistry, Shahid Beheshti University of Medical Sciences, Tehran, Iran \\ ${ }^{5}$ Dental Research Center, Restorative Department, School of Dentistry, Shahid Beheshti University of Medical \\ Sciences, Tehran, Iran
}

\section{*Correspondence to Fahimeh Anbari, Assistant professor, Oral Medicine Department, School of Dentistry, Shahid Beheshti University of Medical Sciences, Tehran, Iran \\ Tel: +989203894001; Email: fahimeh.anbari@gmail. com}

Received: February 28, 2021 Accepted: June 8, 2021 Published online October 19 2021

\begin{abstract}
Introduction: Dentin hypersensitivity $(\mathrm{DH})$ is one of the most common complaints of patients referred to a dental office, so this study aimed to compare the effectiveness of combined diode laser and GLUMA bonding therapy with combined diode laser and 5\% sodium fluoride varnish in patients with $\mathrm{DH}$.

Methods: Sixty patients were divided into three groups (bonding, laser-bonding, laser-varnish), and before the intervention, the amount of $\mathrm{DH}$ was measured with the visual analogue scale (VAS) scale. In the bonding group, GLUMA Desensitizer solution was applied and then air-dried. In the bondinglaser group, first bonding was used, and then the affected tooth was irradiated with a diode laser. In the varnish-laser group, 5\% sodium fluoride varnish was coated and then the laser was irradiated with the said method. DH was measured immediately after the treatment and then 2, 7 and 30 days after the treatment.

Results: Laser-varnish treatment was not different from laser-bonding treatment at all measurement times $(P=1)$. Laser-varnish and bonding treatment were not significantly different up to one week after the intervention, but on the $30^{\text {th }}$ day after the intervention, the difference in pain was significant $(P=0.01)$. There was no significant difference in laser-bonding treatment up to one week after the intervention, but on the $30^{\text {th }}$ day after the intervention, the difference in pain was significant $(P=0.003)$.

Conclusion: The combined treatment with GLUMA bonding and the $660 \mathrm{~nm}$ diode laser is effective in reducing $\mathrm{DH}$ and this is more effective than GLUMA bonding alone in the long term. However, it does not have a significant advantage over the combined varnish-laser method, but it seems that due to its ease of use, it can be a suitable alternative to the varnish-laser method.

Keywords: GLUMA bonding; Sodium fluoride varnish; Dentin hypersensitivity enhancement.
\end{abstract}

\section{Introduction}

Tooth hypersensitivity is one of the most common complaints of patients referred to a dentistry office. ${ }^{1}$

This condition is observed by the patient's complaining about sharp and short-term pain following dental scaling and periodontal surgery and other procedures. It is more common in permanent teeth and disturbs the patient. ${ }^{2}$ The increased sensitivity is mainly due to dentin exposure and hydrodynamic theory.

Dentin is made up of thin tubules which, in normal status, is covered by a layer of enamel, but during enamel removal or gingival resorption which leads to the exposure of the dentinal surface of the tooth root, the dentinal tubules will be exposed to oral cavity environment, and thermal and physical and osmotic stimulants and acidic substances lead to the movements of liquids in dentinal tubules and the activation of nerve endings in these tubules and subsequently sensitizing teeth. ${ }^{3,4}$

Based on this theory, the ideal treatment for dentin hypersensitivity $(\mathrm{DH})$ should be able to decrease intradentin tubules liquid flow or block pulp nerve response. ${ }^{5}$ To date, several methods have been considered to treat

Please cite this article as follows: Asna Ashari M, Berijani A, Anbari F, Yazdani Z, Zandian A. Comparison of the effectiveness of combined diode laser and GLUMA bonding therapy with combined diode laser and $5 \%$ sodium fluoride varnish in patients with dentin hypersensitivity. J Lasers Med Sci. 2021;12:e62. doi:10.34172/jlms.2021.62. 
$\mathrm{DH}$, including the use of desensitizers, ${ }^{6}$ iontophoresis, adhesives, resin, and lasers. ${ }^{7}$

In general, all the desensitizing treatments implement their desensitizing effects through one or two of the following mechanisms.

1. decrease in the flow of dentinal tubular liquid

2. decrease in the activity of dentinal nerves through the interaction of potassium ions with their electrical activity $^{8}$

Recently, lasers have been presented to treat dentinal hypersensitivity in an office. The exact mechanism of lasers in $\mathrm{DH}$ is not clearly understood; however, several theories have been recommended.

Low-intensity lasers like GaAlAs might have photobio-modulation effects on cellular activity, and increase the deposition of tertiary dentin by odontoblast cells. ${ }^{9}$ Lin et al found that the use of lasers in DH treatment was better than the placebo. ${ }^{10}$

Sodium fluoride is one of the most applicable desensitizers to treat $\mathrm{DH}$.

This substance has a short-term performance in blocking or narrowing dentinal tubules, due to gradual effect and its removal it from the tooth surface following brushing. ${ }^{11}$

Dentin Bonding Agents are also used in the treatment of secondary $\mathrm{DH}$ to tooth abrasion, and clinical response to the use of resin bands for appeared cervical dentin with a promising decrease in hypersensitivity is reported. ${ }^{12}$

As bonding systems continue to evolve with improved physical properties, which more effectively block dentinal tubules, these factors might be an appropriate therapeutic option in the permanent improvement of $\mathrm{DH} .{ }^{13}$

To date, numerous studies have investigated the effect of simultaneous use of sodium fluoride $(\mathrm{NaF})$ varnish and lasers ${ }^{14,15}$ and also the use of resin bands ${ }^{16,17}$ to treat hypersensitivity of teeth.

Since no study has assessed the efficacy of combination therapy of laser and bonding thus far and the studies performed have reached no unique treatment protocol for the disease, the aim of this study was to assess the efficacy of the simultaneous use of a laser and $5 \% \mathrm{NaF}$ varnish compared to combination therapy of laser and resin to treat tooth hypersensitivity.

\section{Materials and Methods}

This prospective clinical trial on 60 patients referred to the laser section of the school of dentistry at Shahid Beheshti University of Medical Sciences in Tehran, Iran, was performed randomly and through the split-mouth method.

According to the obtained clinical history, all the patients were appropriately healthy, and on the basis of ASA criteria, they were also in the ASA-1 position.

Those patients of ASA-1, who had at least three teeth with hypersensitivity to contact stimulant and/or air blast and were agreed to 1-month follow-up, were enrolled in the study, and the patients with a history of malignant or benign oral disease, long-term drug use, caries in affected or adjacent teeth, enamel cracking, congenital defects in enamel or dentin, dental restoration, orthodontic procedures, periodontal disease, periodontal surgery or hypersensitivity treatment during last 6 months, nonsurgical treatment of periodontal disease during the 3 months, use of mouthwash or toothpaste containing desensitizers, pregnancy or lactation, use of antidepressants and analgesics, allergy to any components used in the study, bruxism and tooth abrasion were not included in the study.

The measurement of the patients' pain in the study was performed based on the visual analogue scale (VAS) and the pain severity of each patient was recorded prior to performing the intervention.

In order to eliminate the difference in the severity of dentinal hypersensitivity between various types of teeth, the teeth were classified into three groups, and in each of these three therapeutic groups, an equal number of teeth were placed, and then to select the treatment type randomly, one method was allocated from the following three therapeutic methods for each group: (1) bonding, (2) laser-bonding, (3) laser-NaF varnish. In each patient, one insensitive tooth was considered randomly as the control. In the first step, dentinal hypersensitivity was confirmed by blowing cold air in three directions to the tooth for 5 seconds and under the isolation of the tooth.

Then, the tooth was washed with a mixture of water and pumice paste and was dried with sterile gauze.

The tooth was isolated by a cotton roll and the area was prevented from getting wet by strong suction.

\section{Bonding method}

GLUMA desensitizer solution (Kulzer GmbH, Germany) which consists of 5\% glutaraldehyde and 35\% HEMA-G (Hydroxy-Ethyl-Methacrylate and Glutaraldehyde) and distilled water was used. ${ }^{18}$

One droplet of the solution was placed by an applicator for 30 seconds on the tooth.

Then it was blow-dried until the mobile layer on the tooth disappeared and its surface lost the brilliance.

\section{Laser Method}

A KONFTEC Klas-DX diode laser system (KONFTEC Corporation, Taiwan) was used.

The laser with the wavelength of $660 \mathrm{~nm}^{19}$ and power of $15 \mathrm{~mW}$ was radiated to the surface of the affected tooth in the contact mode for 30 seconds from the buccal direction and 30 seconds from the lingual direction. Based on the size of the tooth D or E caps were selected. The energy densities using these two caps are 1.8 and 6.9 $\mathrm{J} / \mathrm{cm}^{2}$ respectively. 


\section{Varnish Method}

On the buccal and lingual surfaces, the tooth was covered by a microbrush of $5 \% \mathrm{NaF}$ (Varnish fluoride, Asia Shimi Teb, Iran). ${ }^{20}$

Then, the patient was explained to avoid eating and drinking in an hour and avoid brushing in 12 hours, and in order to perform this study, 3 therapeutic groups were considered.

In the first group which is the bonding group, in order to match the condition of the intervention, the silent laser was used as the placebo as mentioned above.

The second group or the laser-bonding group underwent the intervention by laser and bonding. First, bonding was done and then the laser was radiated on the affected tooth.

In addition, in the third group or the Laser-Varnish group, varnish was firstly done so and then the laser was radiated. Therapeutic interventions were performed in all groups in two turns of referral daily and the following day.

In order to assess pain perception, a painful stimulant was done using an air blast stimulant by cold air prior to the intervention, immediately after performing the intervention and through intervals of 2, and 7 days and 1 month after performing the treatment intervention in a distance of one centimeter from the dental surface for one second, and the VAS was used to quantify pain severity.

\section{Results}

Sixty patients including 32 women and 28 men participated in this study, and their mean age was 28 years.

Statistical analysis (repeated measure ANCOVA) was performed on the pain severity reported by patients at 5 times: VAS 1.2: the $1^{\text {st }}$ day, after the intervention, VAS
2.1: the $2^{\text {nd }} d a y$, before the intervention, VAS 2.2: the $2^{\text {nd }}$ day, after the intervention, VAS 7: the $7^{\text {th }}$ day, after the intervention, VAS 30: the $30^{\text {th }}$ day, after the intervention). This was done on all the three types of treatment $(B, B+L$, $\mathrm{V}+\mathrm{L}$ ) (Table 1).

Pain severity prior to the treatment in three groups was measured and recorded. The mean and the standard deviation were 4.9 and 2.24 in the Varnish and laser group, 4.61 and 2.16 in the bonding and laser group, and 4.52 and 2.34 in the bonding group. The effect of primary pain (prior to the intervention) was controlled in the analysis.

First, the presence of the reciprocal effect among the variables of the time of assessment with the type of treatment applied was assessed. It was observed that this reciprocal effect at the level of $P=0.185$ was significant, indicating lack of difference between the three groups in the total progress of treatment and representing the positive effect of the three groups on decreasing pain.

In order to assess efficiency (pain severity) among the three groups at each time of the study, type one error was done through the Bonferroni method. Its results are presented in Table 2 and Figure 1. As seen, NaF varnish and laser treatment with bonding and laser treatment were not different at each time of the measurement $(P=1>0.05)$.

Bonding treatment with $\mathrm{Na}-\mathrm{F}$ varnish and the laser were not significantly different until the measurement one week after performing the intervention, but on day 30 after the intervention, this difference was significant $(P=0.01<0.05)$. Bonding treatment with bonding and the laser were not significantly different until the measurement one week after the intervention, but on day 30 after the intervention, this difference was statistically

Table 1. Evaluation of Mean and Standard Deviation of Pain in Different Treatment Groups

\begin{tabular}{|c|c|c|c|c|c|c|}
\hline & & VAS1.2 & VAS2.1 & VAS2.2 & VAS7 & VAS30 \\
\hline \multirow{3}{*}{ Laser-NaF varnish } & Mean & 1.1 & 1.35 & 0.35 & 0.4 & 0.2 \\
\hline & Standard deviation & 1.44 & 1.53 & 0.67 & 0.75 & 0.52 \\
\hline & Number & 20 & 20 & 20 & 20 & 20 \\
\hline \multirow{3}{*}{ Laser-bonding } & Mean & 0.95 & 1.0 & 0.23 & 0.19 & 0.09 \\
\hline & Standard deviation & 1.62 & 1.51 & 0.62 & 0.51 & 0.30 \\
\hline & Number & 21 & 21 & 21 & 21 & 21 \\
\hline \multirow{3}{*}{ Bonding } & Mean & 1.47 & 1.68 & 0.63 & 0.57 & 0.78 \\
\hline & Standard deviation & 2.11 & 2.16 & 1.25 & 1.01 & 0.97 \\
\hline & Number & 19 & 19 & 19 & 19 & 19 \\
\hline
\end{tabular}

Table 2. Evaluation of $P$ Value Comparison in Different Treatment Groups

\begin{tabular}{lcccc}
\hline & VAS1.2 & VAS2.1 & VAS2.2 & VAS7 \\
\hline$P$ value comparison between $B+L$ and $V+L$ & 1 & 1 & 1 & 1 \\
$P$ value comparison between $B$ and $V+L$ & 0.854 & 0.787 & 0.635 & 0.945 \\
$P$ value comparison between $B+L$ and B & 0.742 & 0.322 & 0.381 & 0.245 \\
\hline
\end{tabular}




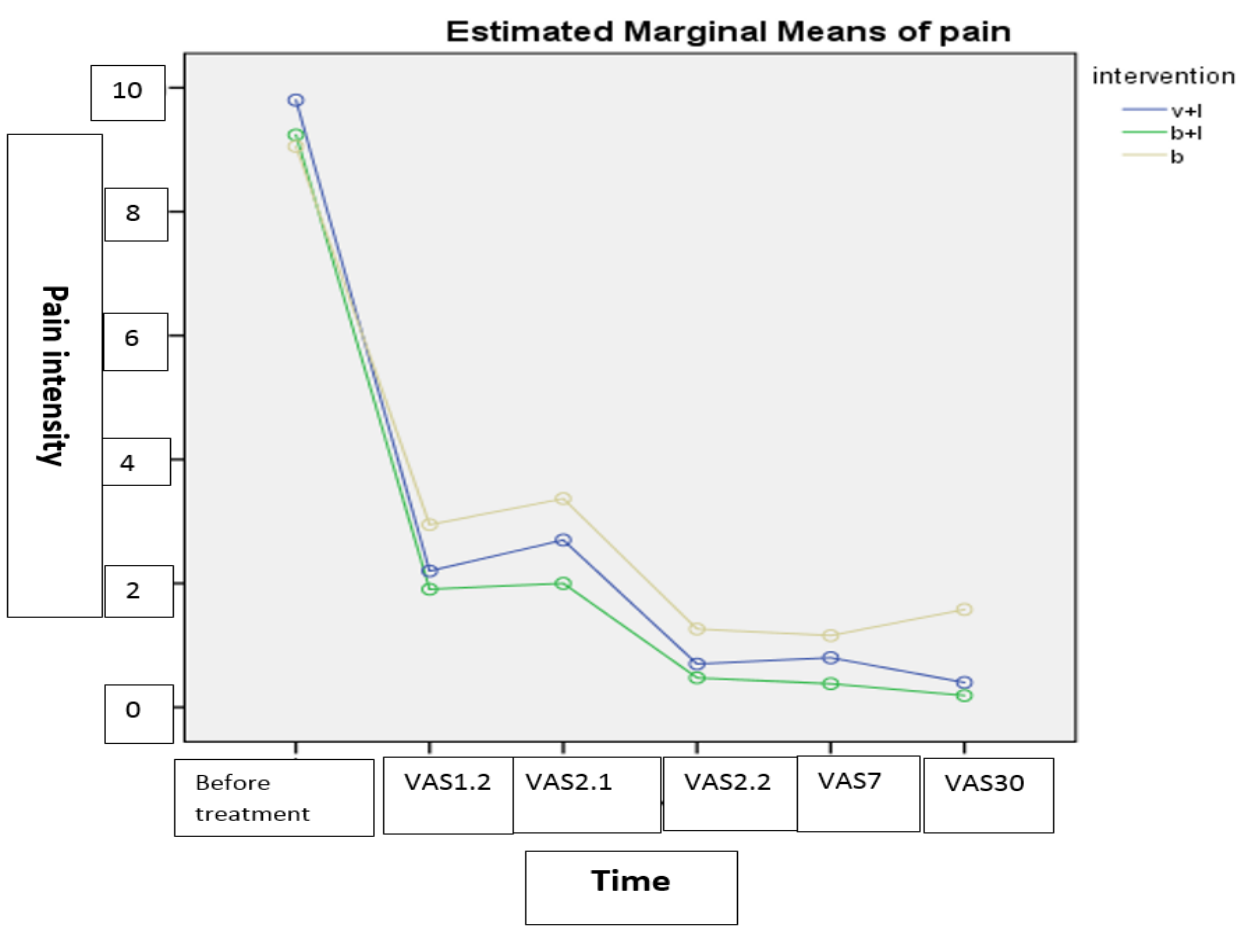

Figure 1. The Effect of Different Treatments on Reducing Pain.

significant $(P=0.003<0.05)$.

\section{Discussion}

$\mathrm{DH}$ is identified by the sharp and temporary pains of dentin exposed to reaction to heating, drying, touching, osmotic or chemical stimulants, which could be attributed to none of the pathologic manners of the tooth. ${ }^{21-23}$ The prevalence of dental hypersensitivity is reported as 15$84 \%$ in various individuals. ${ }^{24}$

In the current study, the effectiveness of three different treatments (GLUMA bonding alone, combined diode Laser and GLUMA bonding therapy, combined diode laser and $5 \% \mathrm{NaF}$ varnish) on pain severity and $\mathrm{DH}$ was assessed.

The results obtained indicated that at the three treatment methods, pain on days one and two decreased; the ratio of pain severity prior to the initiation of the treatment had a significant difference, and this value was reported almost the same at different treatments.

Therefore, a significant difference was not observed among the three mentioned therapeutic methods in decreasing pain, but the decrease in pain in the combination method of bonding-laser was higher than the two other groups. The combination treatments of varnish-laser and bonding-laser decreased pain and DH compared to the first day, and this change was in a descending trend until day 30. Regarding the treatment method of GLUMA bonding, there was a decreasing trend in pain severity until day 7 , but on day 30 , an increase in $\mathrm{DH}$ was observed.

This issue represents stability in decreasing $\mathrm{DH}$ in two combination methods with a laser, but this issue was not correct regarding the bonding method alone. This difference could be attributed to the presence of lasers in both first treatments (varnish-laser and bonding-laser).

In general, in various studies, diode lasers with a wavelength range of 635-830 $\mathrm{nm}$ and a dose range of 2-10 $\mathrm{J} / \mathrm{cm}^{2}$ for $\mathrm{DH}$ were used. ${ }^{25,26}$

High-power lasers melt the dentin at the orifice of dentinal tubules, resulting in their occlusion. The improvement in $\mathrm{DH}$ with the use of low-level lasers is due to their effect on nerve endings and induction of proliferation and differentiation of cells. ${ }^{27}$

Kimura et al stated that the mechanism of decrease in $\mathrm{DH}$ with a laser makes disruption in transmitting sensory messages by C-Fibers. ${ }^{25}$ Tunér and Hode stated that the reduction of hypersensitivity in patients after treatment with these lasers is due to releasing endorphins. ${ }^{28}$

Suri et al. also stated that the simultaneous use of $\mathrm{NaF}$ varnish and the diode laser is effective in decreasing pain according to the VAS, and the effect of simultaneous use was reported more effective than the use of each of these methods separately. ${ }^{20}$ The results of the current study were in line with those in the study by Suri et al. regarding the effectiveness of the combination treatment of $\mathrm{NaF}$ varnish with the diode laser.

In a study by Nemezio et al, it was found that $\mathrm{NaF}$ Varnish and laser GaAIAs are effective in decreasing $\mathrm{DH}$, but the laser is more effective in more severe cases. ${ }^{15}$

The use of resins in decreasing hypersensitivity of teeth in some studies has been assessed. First, Brannstrom et al showed the effectiveness of resin in their studies. ${ }^{16}$ 
This substance blocks the pores of teeth with hypersensitivity by penetrating into dentinal tubules. The main mechanism of this method is to produce protein deposits on the transverse walls of dentinal tubules.

Various later studies have confirmed the efficacy of bonding agents. Tengrungsun and Sangkla in one study with the aim of comparing the efficacy of bonding agents and the GaALAs laser found that both methods were effective but desensitizing effects of bonding were superior. ${ }^{17}$

Numerous studies have shown the positive effects of using GLUMA bonding, diode laser and $\mathrm{NaF}$ varnish on decreasing $\mathrm{DH}$ properly, ${ }^{29,30-34}$ but in these studies, the effect of combination therapy and also the effects of the three methods on decreasing DH have not been compared to each other.

It is obvious that three methods of laser, bonding and varnish alone are able to decrease $\mathrm{DH}$ and pain, and we assessed the combination therapy effects in this research.

Therefore, based on the results of the current study and according to the results of the previous studies, it can be said that the simultaneous and combination use of GLUMA bonding and diode laser in the long term can have better effects on decreasing $\mathrm{DH}$ compared to the combination method of $\mathrm{NaF}$ varnish and diode laser.

\section{Conclusion}

The combination of bonding therapy with GLUMA and a $660 \mathrm{~nm}$ diode laser is effective in decreasing dentinal hypersensitivity, and this is also more effective than GLUMA bonding alone and the combination treatment of $\mathrm{NaF}$ Varnish + diode laser in the long term.

\section{Ethical considerations}

The ethical committee of Shahid Beheshti University of Medical Sciences approved the study (IR.SBMU.DRC.REC.1397.034). Informed consent was obtained from all the patients based on Helsinki Declaration, and they were assured that they could quit the study in case of dissatisfaction and their identity would be preserved over the study. The study is approved by the Iranian Registry of Clinical Trials (identifier: IRCT20201219049759N1).

\section{Conflict of Interests}

The authors declare that they have no conflict of interest.

\section{References}

1. Bartold PM. Dentinal hypersensitivity: a review. Aust Dent J. 2006;51(3):212-8. DOI: 10.1111/j.1834-7819. 2006. tb00431.x

2. Marini I, Checchi L, Vecchiet F, Spiazzi L. Intraoral fluoride releasing device: a new clinical therapy for dentin sensitivity. J periodontol. 2000;71(1):90-5. DOI: 10.1902/ jop.2000.71.1.90

3. West NX, Lussi A, Seong J, Hellwig E. Dentin hypersensitivity: pain mechanisms and aetiology of exposed cervical dentin. Clin Oral Invest. 2013;17(1):9-19. DOI: $10.1007 /$ s00784-012-0887-x
4. Brannstrom M. The hydrodynamics of the dentine. Its possible relationship to dentinal pain. Int Dent J. 1972; 22(2):219-27.

5. Holland G, Narhi MN, Addy M, Gangarosa L, Orchardson R. Guidelines for the design and conduct of clinical trials on dentine hypersensitivity. J Clin Periodontol. 1997 Nov;24(11):808. DOI: 10.1111/j.1600-051x.1997.tb01194.x

6. Lan WH, Liu HC, Lin CP. The combined occluding effect of sodium fluoride varnish and Nd: YAG laser irradiation on human dentinal tubules. J Endod. 1999;25(6):424-6. DOI: 10.1016/S0099-2399(99)80271-4

7. Porto IC, Andrade AK, Montes MA. Diagnosis and treatment of dentinal hypersensitivity. J Oral Sci. 2009;51(3):323-32. DOI: 10.2334/josnusd.51.323

8. Bissada NF. Symptomatology and clinical features of hypersensitive teeth. Arch Oral Biol. 1994;39 Suppl:31S32S. DOI: 10.1016/0003-9969(94)90185-6

9. Tate Y, Yoshiba K, Yoshiba N, Iwaku M, Okiji T, Ohshima $\mathrm{H}$. Odontoblast responses to GaAlAs laser irradiation in rat molars: an experimental study using heat-shock protein-25 immunohistochemistry. Euro j oral sci. 2006 ;114(1):50-7. DOI: 10.1111/j.1600-0722.2006.00261.x

10. Lin PY, Cheng YW, Chu CY, Chien KL, Lin CP, Tu YK. Inoffice treatment for dentin hypersensitivity: a systematic review and network meta-analysis. J Clin Periodontol. 2013;40(1):53-64. DOI: 10.1111/jcpe.12011.

11. Hansen EK. Dentin hypersensitivity treated with a fluoridecontaining varnish or a light-cured glass-ionomer liner. Eur J Oral Sci. 1992;100(6):305-9. DOI: 10.1111/j.16000722. 1992.tb01076.x

12. Ide M, Morel AD, Wilson RF, Ashley FP. The rôle of a dentine-bonding agent in reducing cervical dentin sensitivity. J Clin Periodontol. 1998;25(4):286-90. DOI: 10.1111/j.1600-051x.1998.tb02442.x

13. Schupbach P, Lutz F, Finger WJ. Closing of dentinal tubules by Gluma desensitizer. Eur J Oral Sci. 1997;105(5P1):41421. DOI: 10.1111/j.1600-0722. 1997.tb02138.x

14. Lan WH, Liu HC, Lin CP. The combined occluding effect of sodium fluoride varnish and Nd: YAG laser irradiation on human dentinal tubules. J Endod. 1999;25(6):424-6. DOI: 10.1016/S0099-2399(99)80271-4

15. Nemezio MA, Carvalho SC, Scatolin RS, Colucci V, Galo R, Corona SA. Effect of fluoride varnish combined with Er: YAG laser on the permeability of eroded dentin: an in situ study. Braz Dent J. 2015;26(6):671-7. Doi:10.1590/01036440201300034

16. Brannstrom M, Johnson G, Nordenvall KJ. Transmission and control of dentinal pain: resin impregnation for the desensitization of dentin. J Am Dent Assoc. 1979;99(4):6128. DOI: $10.14219 /$ jada.archive.1979.0337

17. Tengrungsun T, Sangkla W. Comparative study in desensitizing efficacy using the GaAlAs laser and dentin bonding agent. J Dent. 2008;36(6):392-5. DOI: 10.1016/j. jdent.2008.02.012

18. Brahmbhatt N, Bhavsar N, Sahayata V, Acharya A, Kshatriya P. A double blind controlled trial comparing three treatment modalities for denti hypersensitivity $\mathrm{Med}$ Oral Patol Oral Cir Bucal. 2012;17(3): e483-90. DOI: 10.4317/medoral.17594

19. Ladalardo TC, Pinheiro A, Campos RA, Brugnera 
Júnior A, Zanin F, Albernaz PL, Weckx LL. Laser therapy in the treatment of dentine hypersensitivity. Braz Dent J. 2004;15(2):144-50. DOI: 10.1590/s010364402004000200011

20. Suri I, Singh P, Shakir QJ, Shetty A, Bapat R, Thakur R. A comparative evaluation to assess the efficacy of $5 \%$ sodium fluoride varnish and diode laser and their combined application in the treatment of dentin hypersensitivity. $J$ Indian Soc Periodontol. 2016;20(3):307. DOI: 10.4103/0972124x.181243

21. Holland G, Narhi MN, Addy M, Gangarosa L, Orchardson R. Guidelines for the design and conduct of clinical trials on dentine hypersensitivity. J Clin Periodontol. 1997;24(11):808-13. DOI: 10.1111/j.1600-051x.1997. tb01194.x

22. Rees JS. The prevalence of dentine hypersensitivity in general dental practice in the UK. $J$ Clin Periodontol. 2000;27(11):860-5. doi: 10.1034/j.1600051x.2000.027011860.x.

23. Wichgers TG, Emert RL. Dentin hypersensitivity. Oral Health. 1997;87(3):51-61.

24. Absi EG, Addy M, Adams D. Dentine hypersensitivity: a study of the patency of dentinal tubules in sensitive and non-sensitive cervical dentine. J Clin Periodontol. 1987;14(5):280-4. DOI: 10.1111/j.1600-051x.1987. tb01533.x

25. Kimura Y, Wilder-Smith P, Yonaga K, Matsumoto K. Treatment of dentine hypersensitivity by lasers: a review. $J$ Clin Periodontol. 2000;27(10):715-21. DOI: 10.1034/j.1600051x.2000. 027010715.x

26. Sicilia A, Cuesta-Frechoso S, Suárez A, Angulo J, Pordomingo A, De Juan P. Immediate efficacy of diode laser application in the treatment of dentine hypersensitivity in periodontal maintenance patients: a randomized clinical trial. J Clin Periodontol. 2009;36(8):650-60. DOI: 10.1111/j.1600-051x.2009. 01433.x

27. Naghsh N, Kachuie M, Kachuie M, Birang R. Evaluation of the Effects of 660-nm and 810-nm Low-Level Diode Lasers on the Treatment of Dentin Hypersensitivity. J Lasers Med Sci. 2020;11(2):126-34. DOI: 10.34172/jlms.2020.22

28. Tunér J, Hode L. Laser therapy-Clinical practice and scientific background. Prima Books AB;2002.

29. Yilmaz HG, Kurtulmus-Yilmaz S, Cengiz E, Bayindir H, Aykac Y. Clinical evaluation of Er, Cr: YSGG and GaAlAs laser therapy for treating dentine hypersensitivity: A randomized controlled clinical trial. J Dent. 2011;39(3):24954. doi: 10.1016/j.jdent.2011.01.003

30. Etemadi A, Sadeghi M, Dadjou MH. The Effects of Low Level 660nm Laser Irradiation on Pain and Teeth Hypersensitivity after Periodontal Surgery. J Lasers Med Sci. 2011; 2(3):103-8.

31. Sgolastra F, Petrucci A, Severino M, Gatto R, Monaco A. Lasers for the treatment of dentin hypersensitivity: a meta-analysis. J Dent Res. 2013; 92(6):492-9. DOI: $10.1177 / 0022034513487212$

32. Vieira AH, Passos VF, de Assis JS, Mendonça JS, Santiago SL. Clinical evaluation of a 3\% potassium oxalate gel and a GaAlAs laser for the treatment of dentinal hypersensitivity. Photomed Laser Surg. 2009;27(5):807-12. DOI: 10.1089/ pho.2008.2364

33. Dilsiz A, Canakci V, Ozdemir A, Kaya Y. Clinical evaluation of Nd: YAG and 685-nm diode laser therapy for desensitization of teeth with gingival recession. Photomed Laser Surg. 2009;27(6):843-8. DOI: 10.1089/pho.2009.2593

34. Corona SA, Nascimento TD, Catirse AB, Lizarelli RF, Dinelli W, Palma-Dibb RG. Clinical evaluation of low-level laser therapy and fluoride varnish for treating cervical dentinal hypersensitivity. J Oral Rehabil. 2003;30(12):11839. DOI: $10.1111 /$ j.1365-2842.2003. 01185.x 